\title{
Transforming Social Control into Leadership Being the Factor of Providing Welfare
}

\author{
Lubov Ivankina $^{\mathrm{a} *}$, Tatyana Latygovskaya ${ }^{\mathrm{b}}$ \\ *Corresponding author: Lubov Ivankina, ivankina@tpu.ru \\ ${ }^{a}$ Tomsk Polytechnic University, 30, Lenin Ave., Tomsk, 634050, Russia
}

\begin{abstract}
http://dx.doi.org/10.15405/epsbs.2017.01.33

The given work studies the interconnection between social management and leadership in the context of welfare and under the conditions of modernity being the intensive present. It justifies that the reflexivity of modernity expressed in a systemized usage of the knowledge of social life peculiarities being a key component of its arrangement and changing is taking more and more enormous significance under the conditions of transformations taking place at local and global levels. Protection against radical doubting implies orderly practices, obligations for the lifestyles, trust in abstract systems, whose functioning is possible due to the subjective trust phenomenon or generalized mindset with regard to these systems, situations and other individuals.

The basis for analyzing the interconnection of the categories under consideration is composed of value preferences, which contribute to providing the general direction of social transformation, the preference vector of which is directed mainly by the leader. The objective of this paper is to evidence that the factor of welfare provision under the conditions of social control transformation is represented by leadership, which acts as a way of uniting community members with the purpose of collaboration aimed at providing modern society welfare, and designates making decisions contributing to the creation of equal opportunities for the future mankind's survival. In this respect leadership acts as the guarantee of welfare contributing to choosing and setting priorities of human social life.
\end{abstract}

(C) 2017 Published by Future Academy www.FutureAcademy.org.uk

Keywords: Social control; leadership; social control transformation; welfare; civic engagement; value preferences.

\section{Introduction}

The relevance of academic interest to the mentioned problem is based on the impact of social control on the society's quality of life and welfare. The current situation is conditioned by the necessity to set a collective entity of social action. The entity should possess identical will, demonstrate civic engagement corresponding to social order and be able to purposefully change this order, which will affect the social welfare in general. People's life is a directed and continuous process characterized by 
the succession of applying familiar ways to solve various situations, the ways which are codified in a certain culture, and generating new, unfamiliar solutions of real-life problems.

The major distinguishing characteristic of social practices is the demand for subjectivity, which is stipulated by the growing influence of external factors on a human in the situations when they have to find answers to key questions of human existence independently, making choice between the experts' assessments. In the given content the role of civic engagement in social control transformation is directly relating to the leadership being the way of uniting community members. The purpose of uniting is collaboration aimed at providing society welfare, on the basis of choosing solutions which contribute to the creation of equal opportunities for the future mankind's survival. According to Jean Blondel (1992), the leader's mission implies developing visions, setting goals, assigning tasks focusing on persuading people of how important something is, why they need it, what future outcome people can gain in case of behaving the way the leader specifies. In the opinion of C. Hodgkinson (1983) these are leaders who must be able to integrate the intrinsic motives of their followers in their reaching the optimal overviews.

Is it possible to connect the role of civic engagement with leadership and relate it to the modern society welfare? To answer this question let us address the problem of value preferences which contribute to providing the general direction of social transformation, the preference vector of which is directed mainly by the leader.

\section{Interrelation of social control, leadership and welfare}

To understand the importance of leadership in respect to welfare provision under the conditions of social control transformation in the modern society of the intensive present it is required to set a collective entity of social action, which social welfare will depend on. The notion on welfare is traditionally connected with a definite state attained by the society obtaining the basic life necessities. Collective entity of social action can be represented by an integrated and consolidated community (a social corporation) possessing identical will, displaying civic engagement in respect to the existing social order, and able to change it deliberately. And thus, the larger part of society has these qualities, the more effective the transformations seem to be, and, conversely, the smaller part of society has subjectivity, the longer period of time is necessary for implementing the reasonably required transformations.

The role of civic engagement with regard to the existing social order is played by values. This dependence is due to the fact that the events and circumstances united by a subject into a situation having a certain meaning for this subject are the major development determinants. The same idea was expressed by D. Bell (1999), who wrote that ideas and cultural styles do not change the history at least instantly. However, they are a significant prelude to the changes while the alteration in outlook (i.e. alteration in the system of values and moral ground) push people to changing their social relations and institutes.

Social control in its general sense is a cultural element belonging to the system of values and beliefs which trigger the reflection and cause the action of a manager. B. Malinowski (2005) enunciated the law of human nature and culture interrelation. According to the author, culture is a system which 
http://dx.doi.org/10.15405/epsbs.2017.01.33

eISSN: 2357-1330 / Corresponding author: Lubov Ivankina

Selection and peer-review under responsibility of the Organizing Committee of the conference

complies with the human basic needs (Malinowski, 2005). Consequently, culture in its essence, is the system of basic, instrumental and integrative imperatives, including the phenomenon of leadership.

The word "leadership" is of English origin; it has the meaning "to guide" and completely corresponds to its etymology. J. Blondel (1992) interprets "leadership" as the way of uniting community members with the purpose of collaboration aimed at providing modern society welfare. A leader creates the vision, sets goals and tasks, is able to persuade other people as to how important something is, why it is necessary, what impact it will have on their future in case they behave the way the leader prescribes. Accordingly, leadership is the method of influencing people by directing them to reaching a certain goal, and, subsequently, it is a form of control. In this regard, the result of leadership realization is of paramount importance for evaluating its opportunities. And this result can be stated in creating the world people would love to belong to, because basing on the personal view a leader develops the events, attractive for other people due to their importance for these people.

Ontological notion on sociality is connected with the methods of life organization. To unite lots of people into a certain community there should be applied uniting mechanisms, which can enable them to live and act jointly in order to reach integration. In the process of interaction and communication social subjects open up local and global socio-cultural spaces, in which the patterns, norms, rules, values for the life arrangement are being fixed at the level of individual and collective subject. Three significant notions in a categorical sequence of the way of living which is the quality of life, lifestyle and life journey are inherent in everyday practice. Living conditions determining individuals' everyday practices via the quality of life, lead to understanding their behavior and work modes not directly but through the structure of consciousness, its elements represented by needs, interests, system of values.

Within the transformative society characterized by inability of the old system of norms and values to perform its functions and by the new one being in the constant search of institutionalization, these are the preferences of different social groups concerning their values which provide the direction of social transformation. Furthermore, the preference vector in this situation is mainly directed by the leader. The stated dependency was expressed by A. Toynbee (2002) in his law of challenge and response. The leader's activity and image focus on the following social roles: a goals setter, a decision maker and the person who makes these goals become a reality. It is fair to say that leadership has a direct impact on managing the process of the social system self-development by influencing the natural processes. According to the law of challenge and response developed by A. Toynbee (2002), this influence takes place due to the ability of a leader to detect the system target, determined by definite social and cultural, historical and other kinds of backgrounds, which makes this target accessible for the majority of people and directs the social activity to its implementation.

Leadership becomes indispensable when it is necessary to make adequate evaluation of some situation, take a decision, determine upon a course of action and set priorities for the group's activity. Social development and welfare are stipulated by the actions characterized by people's behavior and its purpose. A leader is constantly in the public eye and inside the information flow. And the tasks of a leader is to be able to single out significant information out of the information flow, identify useful signals and transform them into the goals suitable for the others. 
It is obvious that the described process is impossible to implement without the valuable component. According to R. Greenleaf, the followers transform the leader's values into a certain system by transforming them into an internal plan (Robert, 2003). Theoretically, a leader generates the public will. It is no coincidence that one of the missions of a leader consists in making an ethical choice. The latter is made according to the following principle: one should do not what this person wants to do but what needs to be done, guaranteeing a definite range of options.

Thus, the managers' significance is not the managers themselves but their functions in managing public's activity that form and control social norms of behavior displayed by other people. Axiological determinant of leadership is the basis of defining the behavior of the participants engaged in the process organized by a leader and gives efficacy to the ideas, attitudes and values oriented to social welfare.

\section{Axiological leadership as the factor of providing modern society welfare}

There arises the question as to what serves as the basis of leadership managing qualities, and what provides leaders' consolidation and, thus, guarantees the stability of the society welfare? Such a basis is represented by ideas, norms, values and rules. The values of society under continuous changes are construed as showing interests being their basis. Interests are dynamic components of subjects' consciousness and refer to logical methods of perceiving reality, a sense-making area of people's activity. As it was stated by A. Touraine (1998), public life is not controlled by natural or historic laws but is directed by the activity of those who struggle and negotiate the possibility to give a certain social shape to the cultural backgrounds significant for them. Within this framework, the position of N. Lossky (1991), who stated that the value is something pervasive, defining the purpose of the world in general and every person individually as well as every event and every action, seems to be rather interesting.

The recessionary reformed society, in the view of N. Lapin (2000), is subject to changes not only in the system of values but also in their role in society evolution: a new system of the individuals' and social groups' generalized assumptions concerning good and evil, as well as accepted and unaccepted behavioral norms assumes the function of an attractor, a kind of built-in magnet which either keeps society in a chaotic area or draws it out of chaos and pushes it to a new social and cultural state.

In the situation of the growing process destabilization, the tendency of withholding the built relations from destroying begins to dominate and the larger significance is gained by the ability of values to stabilize society.

Social control acts as an ontological concept which registers the measurement results of the public activity being deflected in the process of transformation. The factors capable of transforming social control into leadership being an essential element of social welfare are represented by: growing public activity of all the subjects of control process; changing conditions of social and natural environment; information technologies development; world economy and politics globalization; emphasis on the system of relationships represented by the principle "leader - followers"; the predominance of creative approaches in the system of social control. 
http://dx.doi.org/10.15405/epsbs.2017.01.33

eISSN: 2357-1330 / Corresponding author: Lubov Ivankina

Selection and peer-review under responsibility of the Organizing Committee of the conference

Thus, leadership under the conditions of social control transformation is indispensable as the method of transmitting external factors onto the level of individual behavior of subjects. Leadership being the mechanism of transmitting external impacts on individual behavior of the subjects contributes to forming effective background for social control, which provides the development of modern society in the content of welfare value.

\section{Conclusion}

The given paper justifies the concept of axiological leadership as the factor influencing generation and maintenance of the optimal level of society welfare. It shows that influencing the future by means of choosing an optimal way of development focusing on social activity with the aim of providing welfare, leadership requires attracting the personal aspects of sociogenesis and the mechanism of its functioning. The paper considers the following concept as well: being directly related to personal skills, abilities and influences, leadership, at the same time, acts as the mechanism of social regulating and balancing the opposing interests of actors by means of creating the structure for organizing and streamlining mutual actions of the followers, which we identified with the values influencing the range of actions made by individuals or groups. The following conclusion can be made: leadership, functioning as the way of setting priorities, creates the conditions for implementing the conforming opportunities and, thus, influences welfare of the society as a whole.

\section{Acknowledgements}

This work was performed by the author in collaboration with Tomsk Polytechnic University within the project in Evaluation and enhancement of social, economic and emotional wellbeing of older adults under the Agreement No.14.Z50.31.0029.

\section{References}

Bell, D. (1999). The Coming of Post-Industrial Society. A Venture in Social Forecasting. Moscow: Academia. (in Russian)

Blondel, J. (1992). Political Leadership: Towards a General Analysis. Moscow: Russian Academy of control. (in Russian)

Hodgkinson, C. (1983). The Philosophy of Leadership. Oxford: Blackwell.

Lapin, N.I. (2000). The Problem of Sociocultural Transformation. Russia Studies in Philosophy, 6, 3-17. (in Russian)

Lossky, N. (1991). The History of Russian Philosophy. Moscow: Soviet Writer. (in Russian)

Malinowski, B. (2005). Scientific Theory of Culture. Moscow: United Humanitarian Publishing House. (in Russian)

Robert, K. (2003). Greenleaf the Servant-Leader. Moscow: Publishing house 'Ruby Ray'. (in Russian)

Touraine, A. (1998). The Return of the actor. A sociology essay. Moscow: Scientific World. (in Russian)

Toynbee, A.J. (2002). A Study of History. Moscow: Airis-Press. (in Russian) 